Supporting Information for:

\title{
Synthesis of New Cyclic Dialkoxy Disulfides
}

Nicolas Eghbali, D. Scott Bohle and David N. Harpp*

Department of Chemistry, McGill University, Montreal, Quebec, H3A2K6, Canada

david.harpp@mcgill.ca

Table of Contents: $\quad$ Page

Experimental Procedures $\quad$ S-2

NMR Spectra $\quad$ S-4 


\section{Experimental Section}

Melting points are corrected. Infrared spectra were recorded as $\mathrm{KBr}$ wafers unless mentioned otherwise. ${ }^{1} \mathrm{H}$ NMR spectra were recorded at $300 \mathrm{MHz}$ or $400 \mathrm{MHz}$ as indicated, and ${ }^{13} \mathrm{C}$ NMR spectra were recorded at $75 \mathrm{MHz}$. Samples were made in chloroform- $d$ solvent, and chemical shifts were reported in $\delta$ scale using tetramethylsilane as the internal standard. Coupling constants $J$ are in $\operatorname{Hertz}(\mathrm{Hz})$. Analytical thin-layer chromatography plates (TLC) were ordered from SORBENT technologies, Inc. Visualization of the spots on the TLC plates was achieved by exposure to UV light. Flash chromatography was performed using SILICYCLE 40-63 $\mu \mathrm{m}$ silica gel, and the column was usually eluted with a 2:1 petrolium ether - dichloromethane mixture. For all the reactions dry magnesium sulfate was used as a drying agent after the work-up. Yields refer to the chromatographically isolated yields. Sulfur monochloride was purchased from Aldrich Chemical Co. All the commercial grade reagents were used without further purification. No distillation of sulfur monochloride was performed.

\section{N-Protection of diethyl 3,4-pyrroledicarboxylate (10c).}

In a three neck flask fitted with a water condenser, compound 10c $(2.3 \mathrm{mmol})$ was dissolved in dry THF (10 mL). The solution was cooled to $0{ }^{\circ} \mathrm{C}$ with an ice bath before the successive addition of $t$-BuOK (2.6 mmol added slowly) and 1-bromopropane (2.6 mmol). The mixture was stirred for 5 min. The ice bath was removed and the reaction mixture heated to reflux for $2 \mathrm{~h}$. After cooling to room temperature, the product was extracted with dichloromethane. Diethyl 1-propyl 3,4-pyrroledicarboxylate (10d) was 
isolated pure as an orange oil after solvent removal (72\% yield) and used directly without further purification. ${ }^{1} \mathrm{H}$ NMR (300 MHz, $\left.\mathrm{CDCl}_{3}\right) \delta 0.83(\mathrm{t}, 3 \mathrm{H}, J=7.5 \mathrm{~Hz}), 1.25(\mathrm{t}, 6 \mathrm{H}, J$ = $6.9 \mathrm{~Hz}), 1.72(\mathrm{~m}, 2 \mathrm{H}), 3.74(\mathrm{t}, 2 \mathrm{H}, J=7.2 \mathrm{~Hz}), 4.19(\mathrm{q}, 4 \mathrm{H}, J=6.9 \mathrm{~Hz}), 7.12(\mathrm{~s}, 2 \mathrm{H})$;

${ }^{13} \mathrm{C}\left(75 \mathrm{MHz}, \mathrm{CDCl}_{3}\right) \delta 11.30,14.70,24.50,52.20,60.30,116.00,127.90,163.70$, HRMS calcd for $\mathrm{C}_{13} \mathrm{H}_{19} \mathrm{NO}_{4}$, 253.1314, found, 253.1322.

\section{Reduction of diethyl 1-propyl 3,4-pyrroledicarboxylate (10d).}

In a three neck flask fitted with a water condenser, LAH $(1.7 \mathrm{mmol})$ was suspended in 5 $\mathrm{mL}$ of dry THF. After the solution was cooled at $0{ }^{\circ} \mathrm{C}$ in an ice bath, a solution of compound 10d $(1 \mathrm{mmol})$ in dry THF $(10 \mathrm{~mL})$ was added slowly with a syringe. The mixture was stirred 5 min at $0{ }^{\circ} \mathrm{C}$ before being heated to reflux for $2 \mathrm{~h}$. After cooling to room temperature, the classical Fieser work-up was performed (quentching with water and aqueous $\mathrm{NaOH}$ ). The resulting suspension was filtrated and washed with hot THF. A colorless or sometimes slightly orange oil was obtained after solvent removal. Compound 10a (85\% yield) was isolated and used without further purification. ${ }^{1} \mathrm{H}$ NMR $(400 \mathrm{MHz}$, CDCl3) $\delta 0.87(\mathrm{t}, 3 \mathrm{H}, J=7.2 \mathrm{~Hz}), 1.72(\mathrm{~m}, 2 \mathrm{H}), 3.70(\mathrm{t}, 2 \mathrm{H}, J=6.8 \mathrm{~Hz}), 4.45(\mathrm{~s}, 2 \mathrm{H})$, $6.55(\mathrm{~s}, 2 \mathrm{H})$.

NMR Spectra for compounds: 7b, 8b, 9b, $10 b$ and $15 b$ 


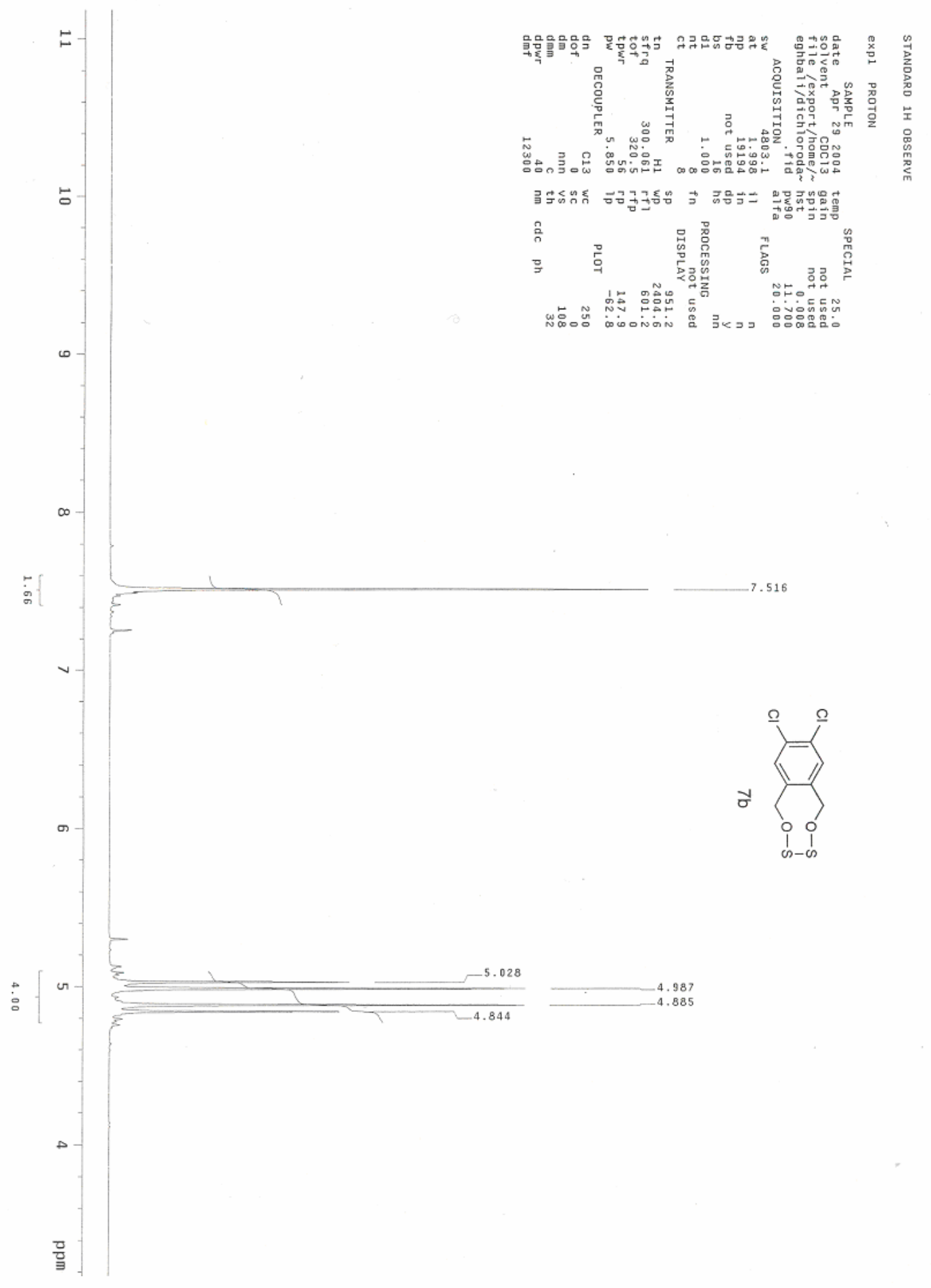




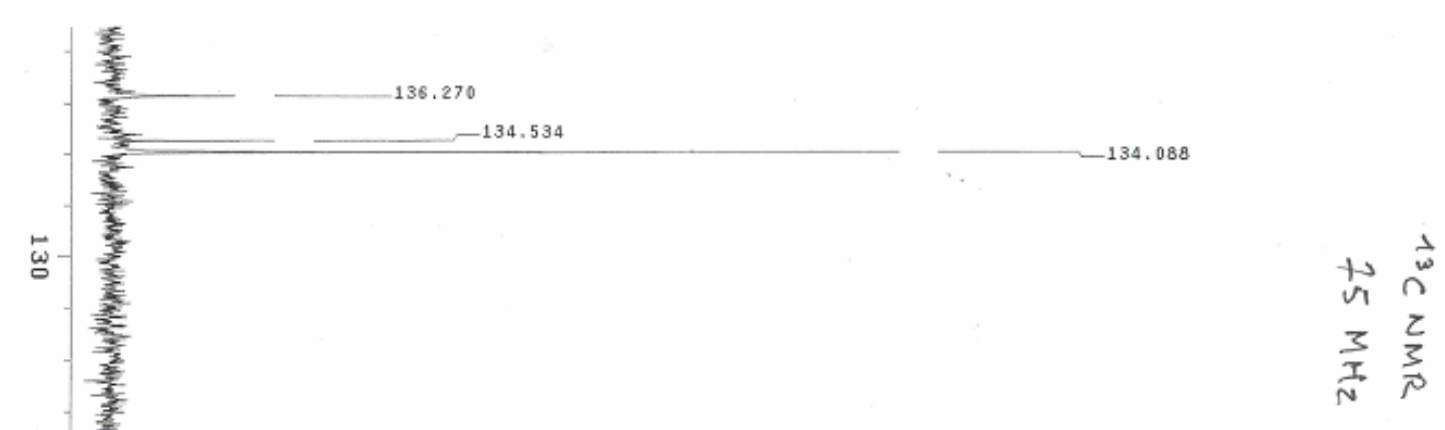

ํ.

-

旁
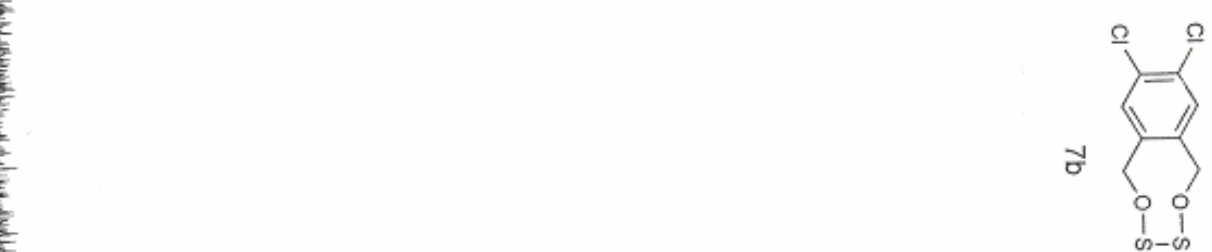

,

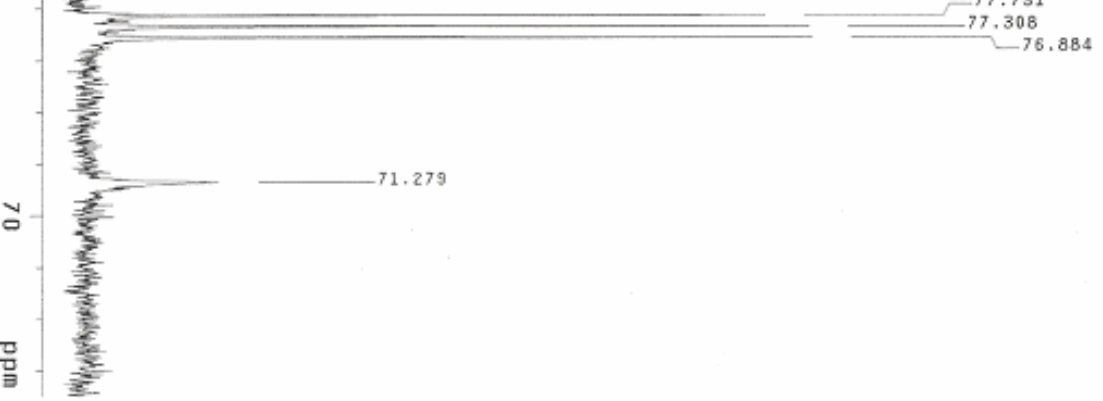




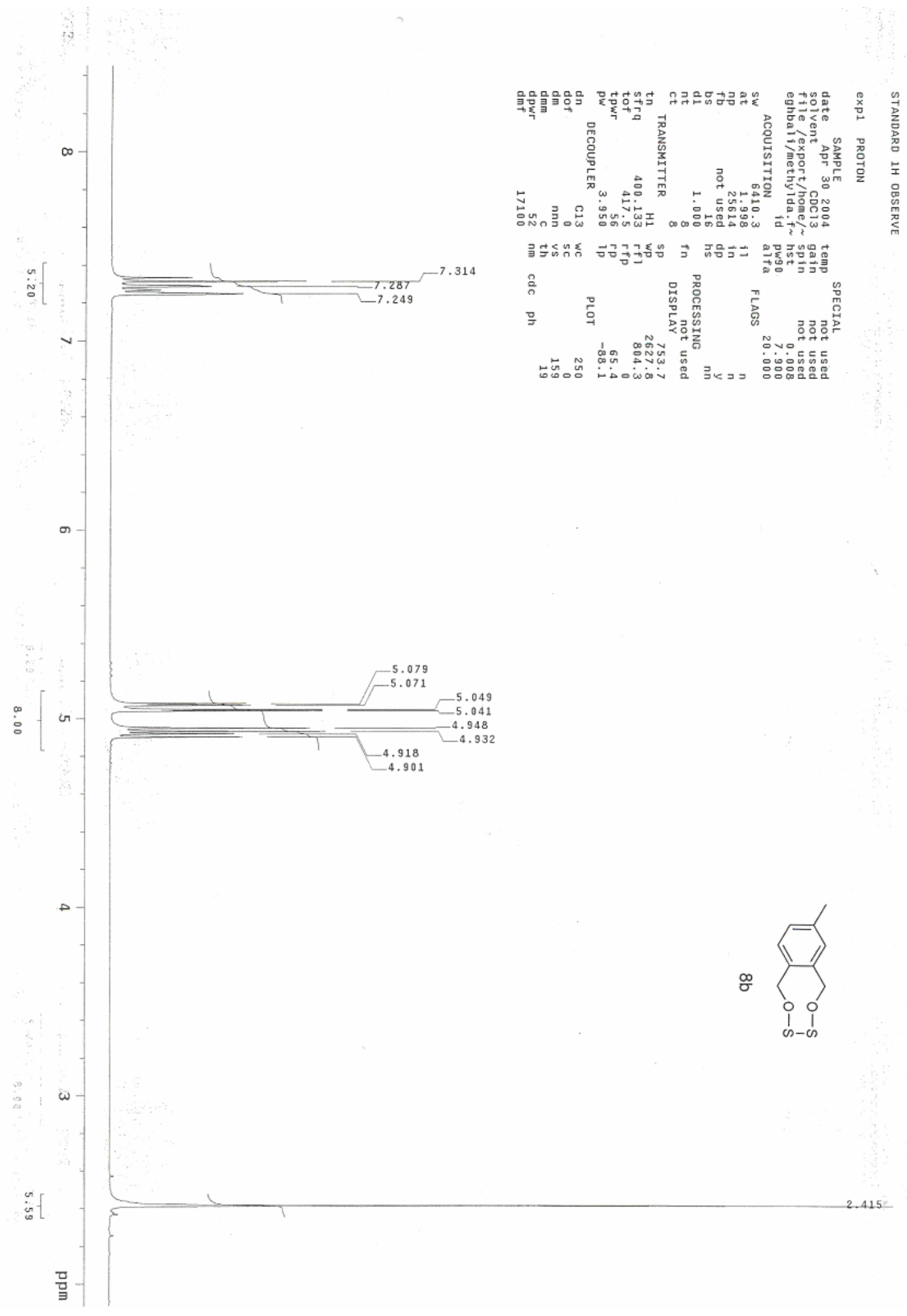




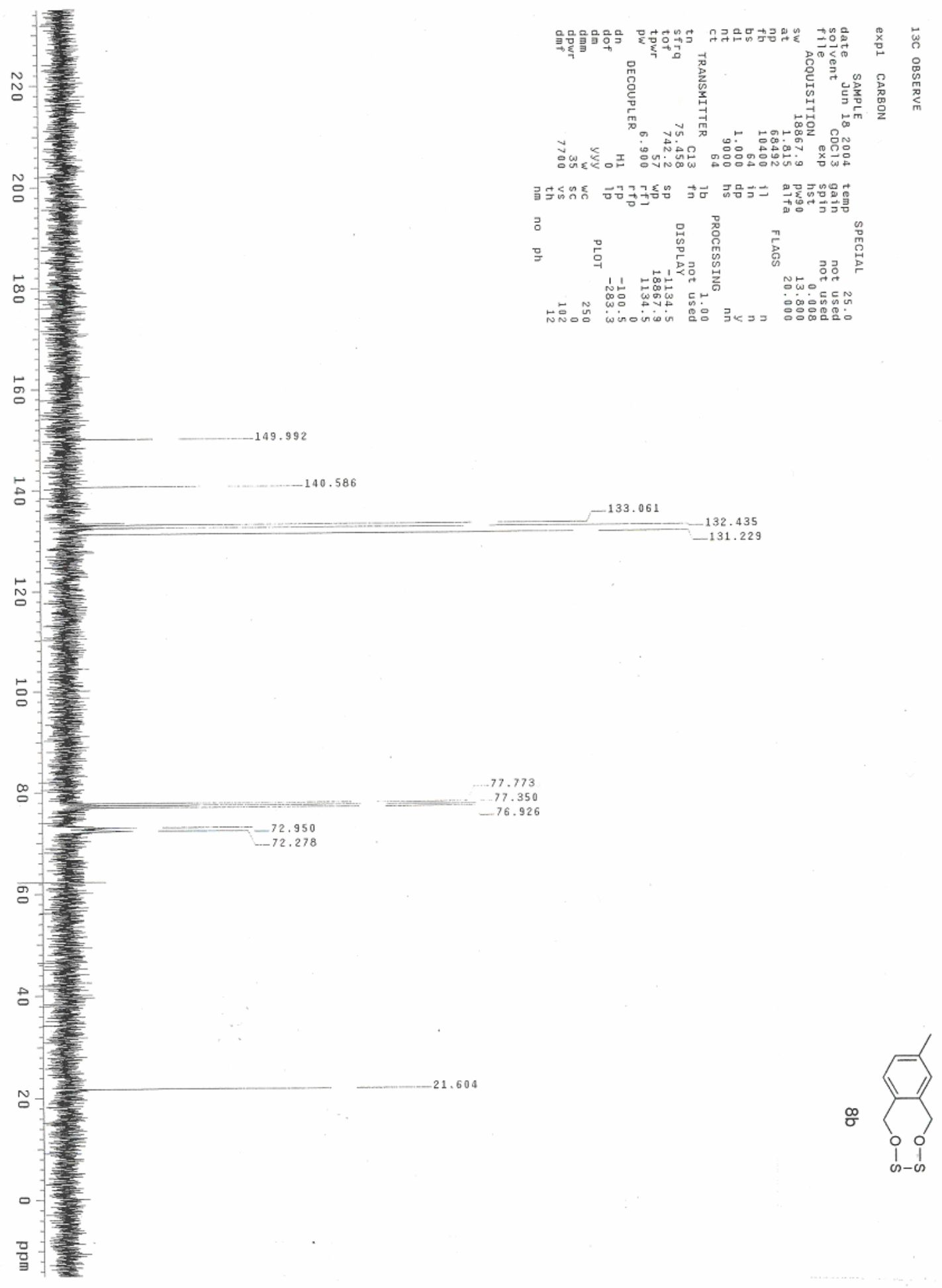




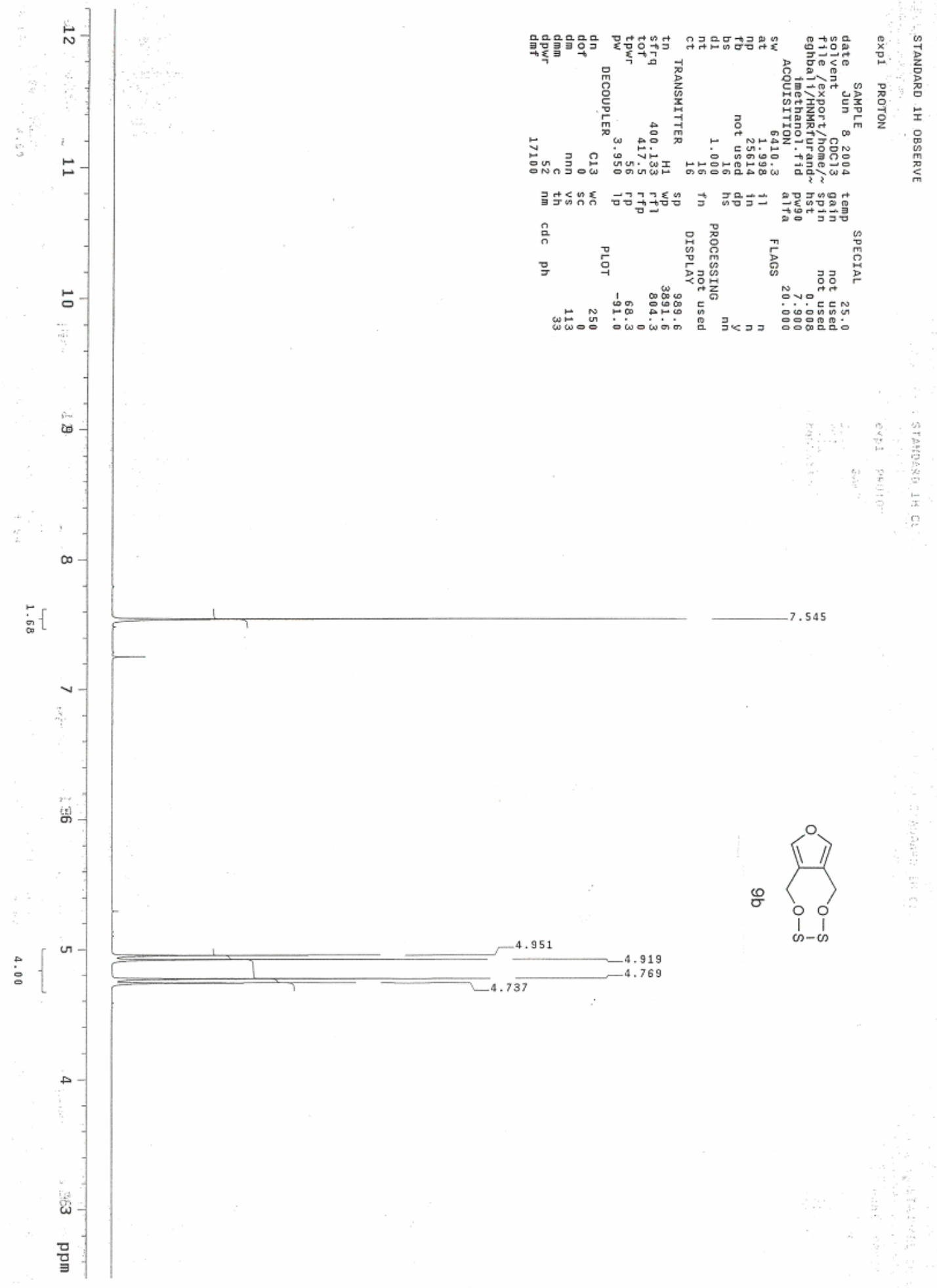




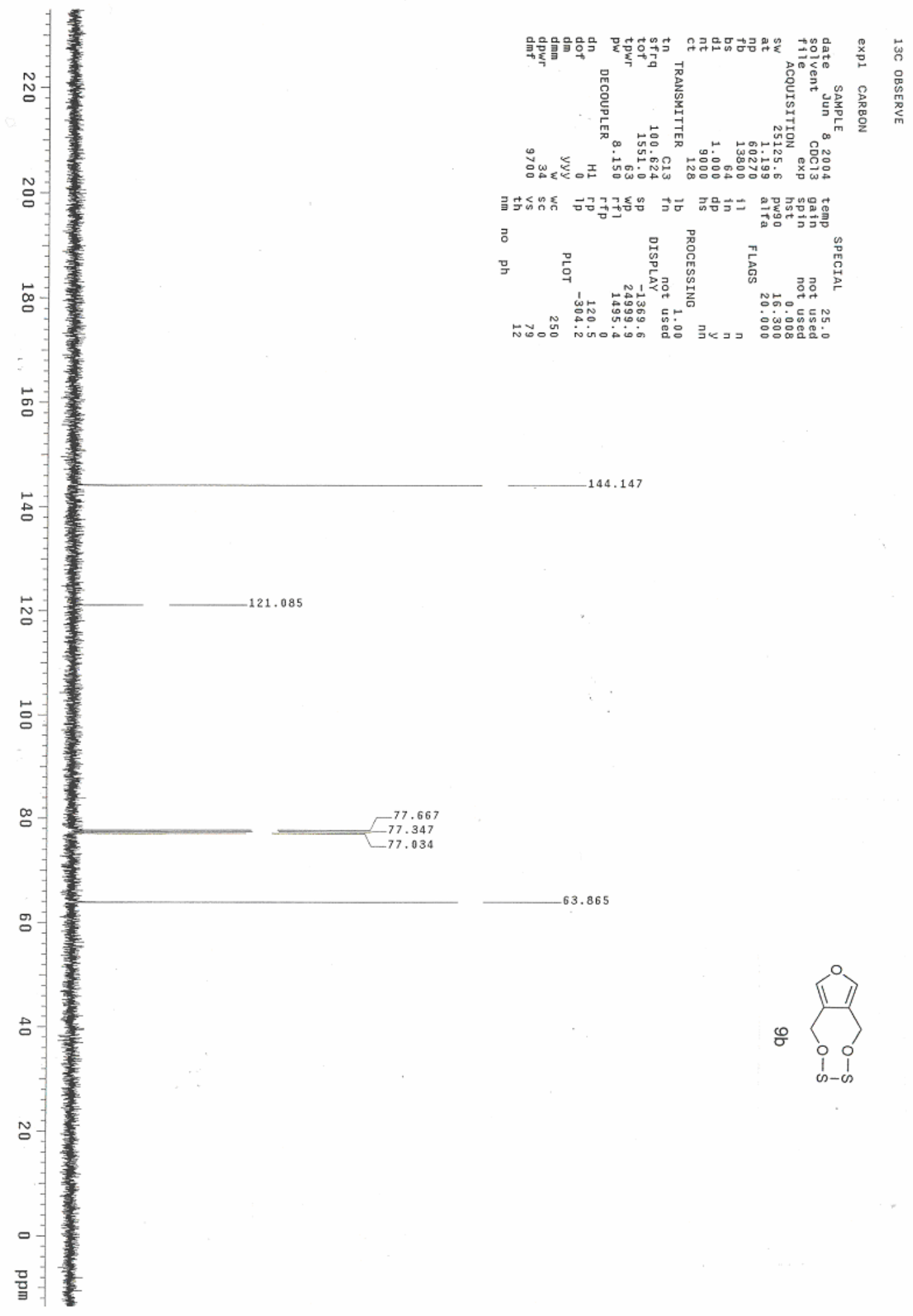




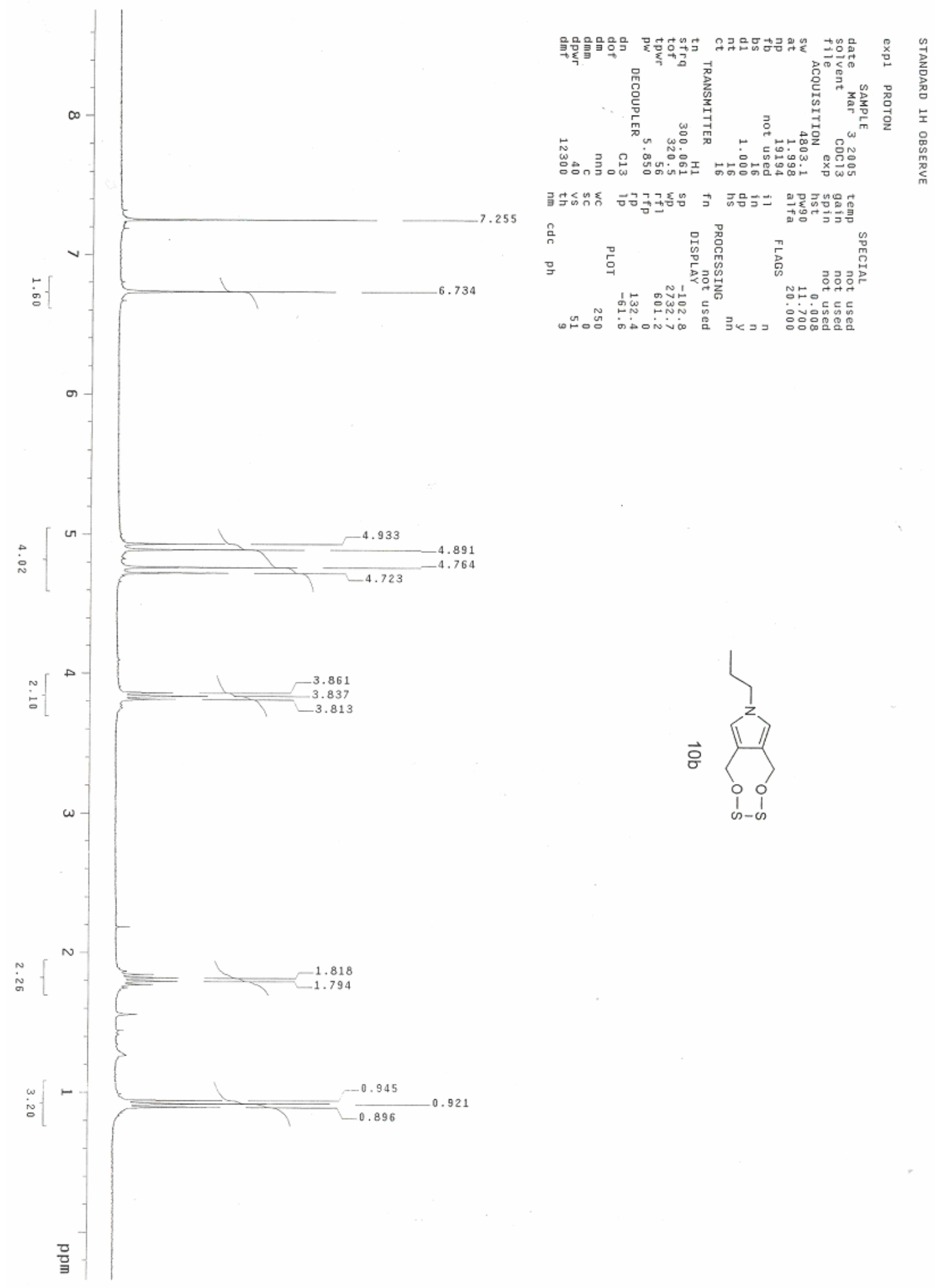




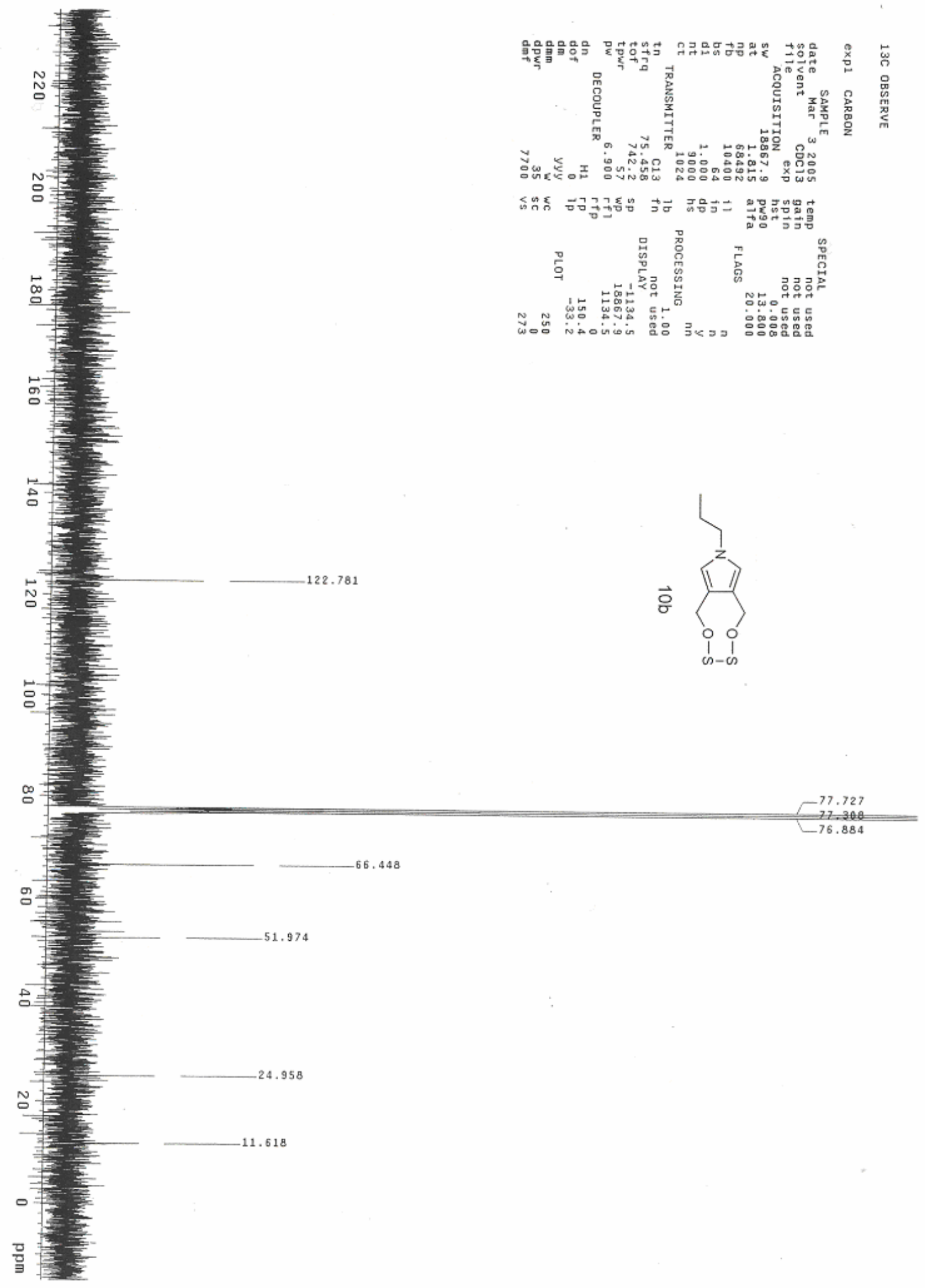




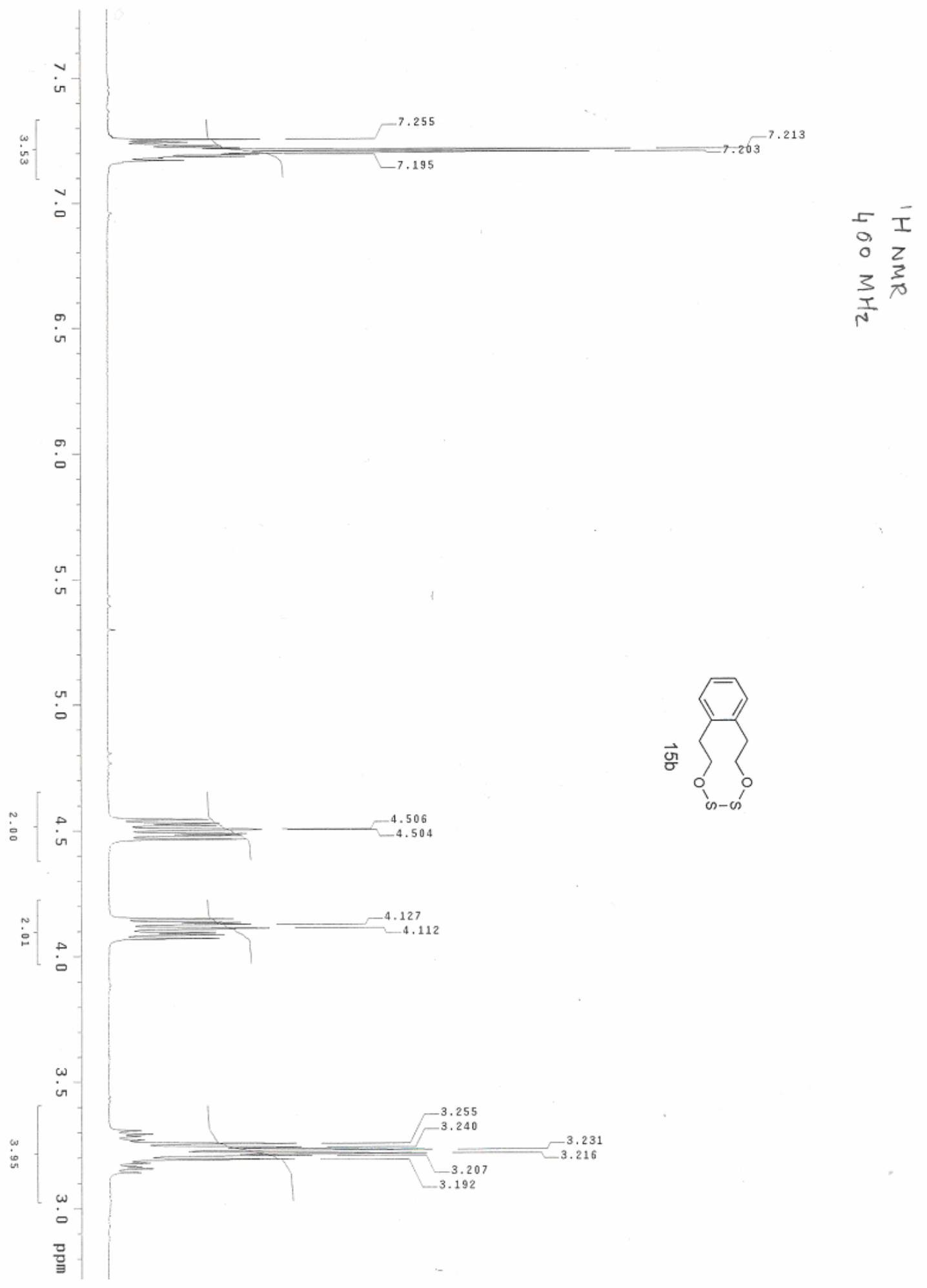

S-12 


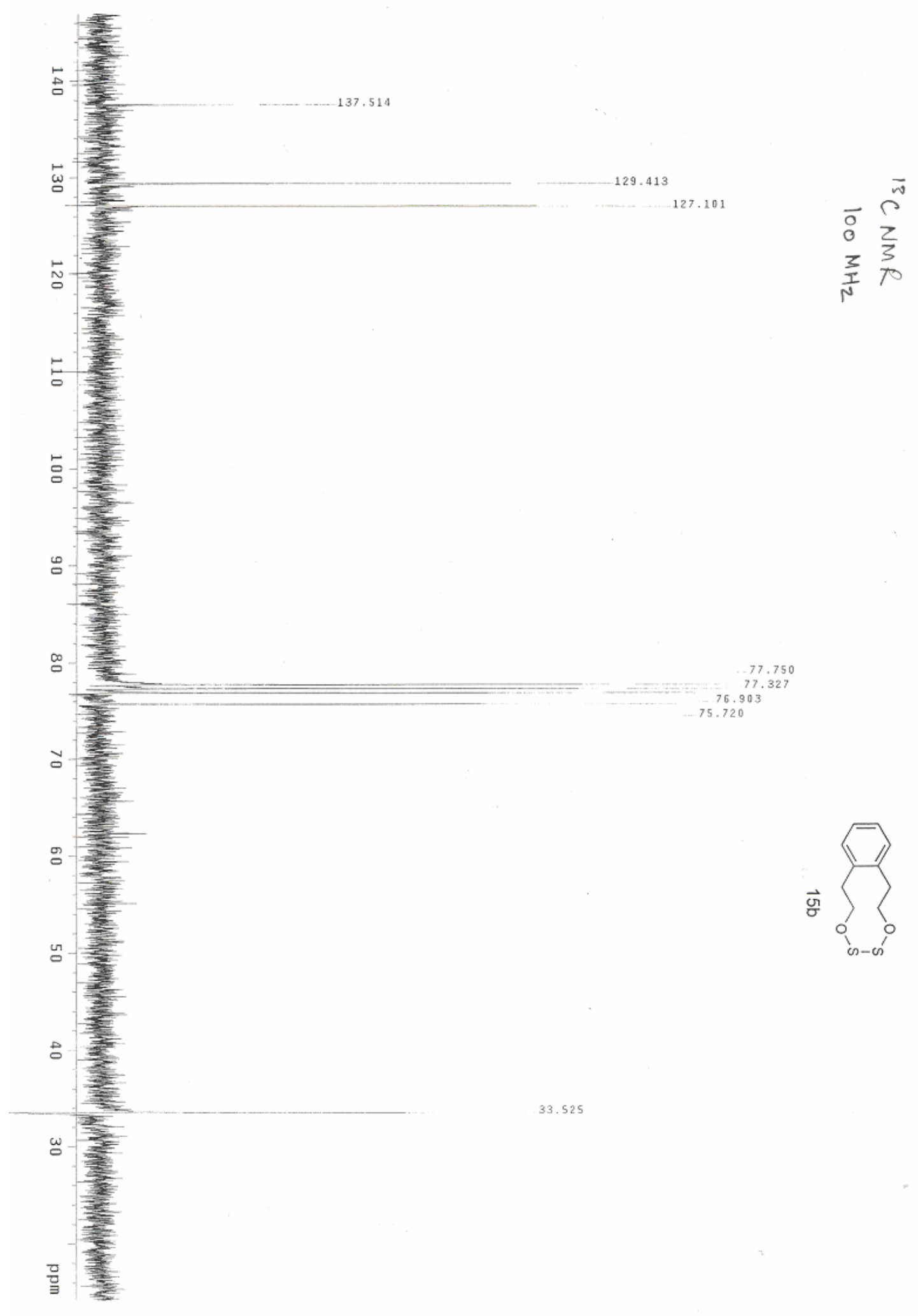

S-13 